\title{
Development of Life-cycle Detection and Extending Function for Reusing Automotive Lithium-ion Battery - Verified in 52V LiMnNiCoO2 Platform
}

Wu-Yang Sean ( $\nabla$ wysean@cycu.org.tw )

Chung Yuan Christian University https://orcid.org/0000-0001-9742-8529

\section{Ana Pacheco}

Chung Yuan Christian University

\section{Research}

Keywords: Battery Management System (BMS), Reused Lithium-lon Battery, Adaptive control algorithm, Ultracapacitor, Life-cycle estimation, Life-cycle extension

Posted Date: April 2nd, 2020

DOl: https://doi.org/10.21203/rs.3.rs-20563/v1

License: (c) (i) This work is licensed under a Creative Commons Attribution 4.0 International License.

Read Full License 


\title{
Development of Life-cycle Detection and Extending Function for Reusing Automotive Lithium-ion Battery - verified in 52V LiMnNiCoO 2 Platform
}

\author{
Wu-Yang Sean1)*, Ana Pacheco1) \\ 1) *Department of Environmental Engineering, Chung Yuan Christian University, 32023, Chung-Li, Taiwan
}

\begin{abstract}
For reusing automotive lithium-ion battery, an in-house battery management system is developed. To overcome the issues of life cycle and capacity of reused battery, an online function of estimating battery's internal resistance and open-circuit voltage based on adaptive control theory are applied for monitoring life cycle and remained capacity of battery pack simultaneously. Furthermore, ultracapacitor is integrated in management system for sharing peak current to prolong life span of reused battery pack. The discharging ratio of ultracapacitor is adjusted manually under Pulse-Width-Modulation signal in battery management system. In case study in $52 \mathrm{~V} \mathrm{LiMnNiCoO}_{2}$ platform, results of estimated open-circuit voltage and internal resistances converge into stable values within 600(s). These two parameters provide precise estimation for electrical capacity and life cycle. It also shows constrained voltage drop both in the cases of $25 \%$ to $75 \%$ of ultracapacitors discharging ratio compared with single battery. Consequently, the Lifecycle detection and extending functions integrated in battery management system as a total solution for reused battery are established and verified.
\end{abstract}

KEY WORDS : Battery Management System (BMS), Reused Lithium-Ion Battery, Adaptive control algorithm, Ultracapacitor, Life-cycle estimation, Life-cycle extension

\section{NOMENCLATURE}

ECM : electrical circuit model

$v_{b}$ : voltage of battery, A

$v_{o c}$ : open-circuit voltage, $\mathrm{V}$

$R_{s}:$ first-order, ohm

$R_{t}:$ second-order, ohm

$i_{b}:$ battery current, A

$v_{c}$ : voltage across $\mathrm{RC}$ circuit, $\mathrm{V}$

IRs: current across RC curcuit based on ECM, A

SoC : state of charge, \%

$\mathrm{T}$ : temperature, $\mathrm{K}$

$\mathrm{h}:$ historical data

$u$ : adjustable for input parameters

$\theta$ : estimated results of target parameters

$\mathrm{C}_{\mathrm{t}}$ : first-order capacitance based on ECM, C subscripts

b, c, oc, s, t : battery, capacitance, open-circuit, first-order, second-order parameter based on ECM

*Corresponding author. e-mail: wysean@cycu.org.tw

\section{INTRODUCTION}

In Taiwan, electric vehicle (EV) demand has increased significantly. Lithium-ion batteries (LIBs) are currently used in the majority of EV. LIBs contain rare metals ex. lithium, manganese or cobalt. According to the regulation of $\mathrm{EV}$, the battery pack in $\mathrm{EV}$ are scrapped for driving if lower than $80 \%$ of their fresh electrical capacity is left. After discarded from EVs, LIBs can be used for stabilizing solar and wind power or frequency regulation (US EPA 2010). It is also competitive if to integrate LIBs for shaving the peak pulse of the grid (Sean et al. 2010; Wu et al. 2009).

For retarding the aging of RLIB, Battery management system (BMS) with online monitoring functions, i.e. DC internal resistance (IR) and open-circuit voltage (OCV) is proposed (Chiang et al. 2017, 2019). ECM (equivalent circuit model) are generally adopted in dynamic system and applications of battery (Chiang et al. 2011; Pei et al. 2014; Feng et al. 2014; Plett et al. 2004; Xiong et al. 2013; $\mathrm{Li}$ et al. 2015). The electrical response of battery can be simulated as state-space structure (Chiang et al. 2011). State of health $(\mathrm{SoH})$ is defined as the battery response comparing its fresh condition, and used parameter of IR to show its aging. In relative researches (Chiang et al. 2011; Pei et al. 2014; Feng et al. 2014; Plett et al. 2004; Xiong et al. 2013; Li et al. 2015; Feng et al. 2015; Lu et al. 2013), modern control theory is applied to monitor online DC IR and OCV that relates SoH and state of charge (SoC) simultaneously. The algorithm implemented in BMS aims at estimating the life cycle and remained capacity of new battery. A simple circuit by using ultracapacitor (UC) is reported in research (Chiang et al. 2017). This converterless parallel circuit of BMS performs active control of RLIB by applying UC. BMS pays an important role of managing power flow between battery and UC. The discharge ratio of UC load is generated a Pulse Width Modulation (PWM) signal to control the occupying time of fast switch module. It 
shows merits of simple, cheap, and easy to arrange in large-scale application. In this research, voltage drop or depth of discharge (DoD) are used as a reference index of $\mathrm{SoH}$.

For managing RLIB, an integrated BMS is developed and verified in this study. An online function of estimating RLIB's internal resistance (IR) and open-circuit voltage (OCV) simultaneously based on adaptive control theory are implemented in hardware for monitoring the life cycle and remained capacity of RLIB for compensating weaknesses of lower discharge current and short life cycle. For extending RLIB's life cycle, UC is used as an auxiliary battery to share the high load current by adjusting PWM signal in hardware. The results of online monitoring IRs and OCV is presented to indicate the life cycle and SoC of RLIB. The merit of connecting UC with RLIB is capable of reducing voltage drop or so-called DoD can be expressed in term of IRs. Besides, OCV curve is an indispensable curve for calculating percentage of remained capacity of battery. In this study, it can be online obtained easily by adaptive control algorithm.

\section{METHODS}

Based on historic log file and online measured IR, RLIB is packed by in-house BMS as shown in Fig. 1. RLIB is in parallel connection with UC controlled by PWM signal. IR and OCV are obtained by adaptive control algorithm simultaneously. The schematic procedure is illustrated in Fig. 2. It is briefly summarized as below. The battery voltage can be expressed as:

$$
\begin{aligned}
\dot{v}_{b} & =\dot{v}_{o c}-\dot{R}_{s} \dot{i_{b}}-R_{s} \dot{i_{b}}-\dot{v}_{c} \\
& =\sigma\left(v_{o c}\right) x-\sigma\left(R_{S}\right) x \dot{i}_{b}-R_{s} \dot{i_{b}}-\dot{v}_{c}
\end{aligned}
$$

Here, $\sigma(p)=\left[\frac{\partial p}{\partial S o C} \frac{\partial p}{\partial T} \frac{\partial p}{\partial h}\right]$

$x^{T}=\left[\frac{\partial S o C}{\partial t} \frac{\partial T}{\partial t} \frac{\partial h}{\partial t}\right]$

Here, $v_{b}, v_{o c}, R_{s}, R_{T}, i_{b}$ and $v_{c}$ mean voltage of battery, open-circuit voltage, first-order and second-order Irs, battery current and voltage across RC curcuit based on electrical circuit model (ECM) as shown in Fig. 3. The projected parameters $v_{b}$ and $R_{s}$ is assumed as function of $S o C$, T, and h change with time. In addition, Eq. (1) can be simplified with the following assumptions:

(1) Small deviation of every battery's discharge is assumed compared to totally useful capacity, thus $\partial \mathrm{SoC} / \partial \mathrm{t} \approx 0$.

(2) In normal operating conditions, deviation of cell temperature, $\mathrm{T}$ is slow by using fan, thus $\partial \mathrm{T} / \partial \mathrm{t} \approx 0$.

(3) A long-time usage history, $\mathrm{h}$ is performed, thus $\partial \mathrm{h} / \partial \mathrm{t}$ $\approx 0$.

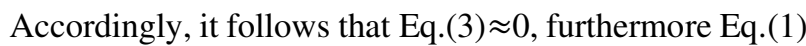
can be rewritten as:

$$
\begin{aligned}
& \dot{v}_{b}=\left(\frac{\partial v_{o c}}{\partial S o C} \frac{\partial S o C}{\partial t}+\frac{\partial v_{o c}}{\partial T} \frac{\partial T}{\partial t}\right)-\left(\frac{\partial R_{S}}{\partial S o C} \frac{\partial S o C}{\partial t}+\frac{\partial R_{S}}{\partial T} \frac{\partial T}{\partial t}\right) i_{b} \\
& =-\frac{1}{C_{t} R_{t}} v_{b}-R_{S} i_{b}-\frac{R_{t}+R_{S}}{C_{t} R_{t}} i_{b}+\frac{v_{o c}}{C_{t} R_{t}}
\end{aligned}
$$

Eq.(4) can also be written as a vector form.

$$
\begin{aligned}
& \dot{v}_{b}=\theta^{T} X \\
& \theta^{T}=\left[\begin{array}{llll}
\theta_{1} & \theta_{2} & \theta_{3} & \theta_{4}
\end{array}\right]^{T}=\left[\begin{array}{ll}
R_{s} & \frac{R_{s}+R_{t}}{C_{t} R_{t}} \frac{1}{C_{t} R_{t}} \frac{v_{o c}}{C_{t} R_{t}}
\end{array}\right] \\
& X^{T}=\left[\begin{array}{lll}
-\dot{i}_{b}-i_{b}-v_{b} & 1
\end{array}\right]
\end{aligned}
$$

Eq.(6) is rewritten as Eq.(8) with repect to every estimated state $\dot{\hat{v}}_{b}$

$\dot{\widehat{v_{b}}}=\hat{\theta}^{T} \hat{X}+u$

where $\hat{X}^{T}=\left[-\dot{i}_{b}-i_{b}-\hat{v}_{b} 1\right], u$ is adjustable for input parameters. $\theta$ is estimated results of target parameters. Adaptive control algorithm is based on tracking input signals to modify the target parameters in control states, so that the convergent criteria is satisfied as below:

$\lim _{\mathrm{t} \rightarrow \infty} e=\lim _{\mathrm{t} \rightarrow \infty}\left(v_{b}(t)-\widehat{v_{b}}(t)\right)=0$

Here, $R_{t}$ and $C_{t}$ mean first-order IR and capacitance based on ECM. If thermal effect of temperature was not considered, $\partial \mathrm{T} / \partial \mathrm{t} \approx 0$ is obtained.

Adaptive control algorithm shown in Figure 2 is introduced to optimize the unknown target parameters of $R_{s}, R_{t}$ and OCV in Eq. (4). By using Lyapunov function, the direct measurements such as working current and voltage are used for extracting battery IR and OCV. A filtering process is here to improve the measured noise and enhence the estimation reliability. In estimation process, IR is a sensitized parameter of life cycle, hence it is used to indicate the deviation of life cycle. OCV curve related to the battery's useful capacity is applied to estimate the remained capacity of SoC. The algorithm is discretizated, and embeded in BMS.

\section{EXPERIMENT}

A max-52V LiMnNiCoO 2 lithium-ion battery pack with in-house BMS is used in the platform. This automotive battery pack is generally used as a module for electric vehicle, and the specification is listed in Table 1 . The overall platform is composed of battery pack, max-60V DC source, DC load, CAN analyzer and PC interface as shown in Fig. 4. The in-house BMS is embedded with 
life-cycle detection and extending function. The working current and voltage drop of battery pack are monitored by both BMS and DC source simultaneously.

\section{RESULTS AND DISCUSSION}

Figure 5-7 show one result for examining the adaptive control algorithm to estimate OCV and IRs $\left(\mathrm{R}_{\mathrm{s}}+\mathrm{RT}_{\mathrm{T}}\right)$. Fig. 5 shows working voltage(upper), working current(middle), and convergent error(bottom) of $10 \mathrm{Ah} / 52 \mathrm{~V}$ battery pack in the platform. The bottom figure in Fig. 5 satisfies Eq. (9). Through adaptive control before filtration, the relative result of target parameters, $\theta^{T}=\left[\begin{array}{llll}\theta_{1} & \theta_{2} & \theta_{3} & \theta_{4}\end{array}\right]^{T}$ in Eq. (6) is shown in Fig. 6. The convergent trend can be observed in the figure. Online estimation of SoH-sensitized parameter $\mathrm{R}_{\mathrm{s}}$ and $\mathrm{R}_{\mathrm{T}}$ converge into stable value in $600(\mathrm{~s})$ as shown in Fig. 7 (upper and bottom). The simultaneous result of estimated open-circuit voltage (OCV) is listed in Fig. 7 (middle). Fig. 8 shows result of voltage drop by measuring battery and system side simultaneously. The peak current resulting in voltage drops between battery and system in Fig. 8 is compensated by UC. In addition, the deviation between battery and system in Fig. 8 is due to the voltage drop consumed by harness. The voltage drop of about $47.3 \sim 48.3 \mathrm{~V}$ regarding discharging ratio of $25 \%$ battery $+75 \%$ UC in Fig. 8 corresponds to the bottom line in Fig. 9. Comparison of measured voltage drop and estimated $\mathrm{OCV}$ of battery in cases of discharging ratio $0 \%, 25 \%$, and $75 \%$ is summarized in Fig. 9. Estimated results of $\mathrm{OCV}$ in three cases are consistent with static voltage drop. Here, UC contributes constrained voltage drop. Without UC, it becomes gentle slope of voltage drop, and peak current causes wider voltage range that results in the shortage of life span.

\section{CONCLUSION}

For verifying functions of online monitoring and extending life cycle of in-house BMS for RLIB, one $52 \mathrm{~V}$ $\mathrm{LiMnNiCoO}_{2}$ platform is established for testing. The solution of extending life span regarding battery is to use one suitable UC parallelly connected with BMS. The discharging ratio between battery and UC is adjusted manually by PWM signal. Particularly, adaptive control algorithm is applied for estimating OCV and IRs (Rs, RT) that concern with parameters of SoC and SoH. In bench test, estimated OCVs are consistent with measured static voltage drops, and estimated IRs show deviation within $5 \%$ in test cases. It is obvious that UC contributes constrained voltage drop so as to prolong life span of battery. Consequently, this study examines the effectiveness of in-house BMS for RLIB. Next phase, a pilot run to install small-scale RLIB in electric vehicle is on schedule. For optimizing energy efficiency, several cases of using different PWM signal is planned to road test. It will support in choosing proper discharging ratio of battery for obtaining a minimum voltage range of RLIB.

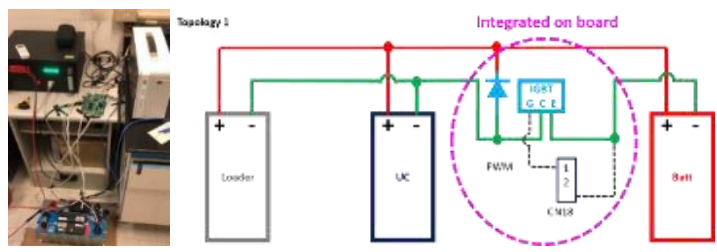

Figure 1. Battery(Batt in figure) in parallel connection with UC(ultracapacitor) controlled by PWM integrated in BMS

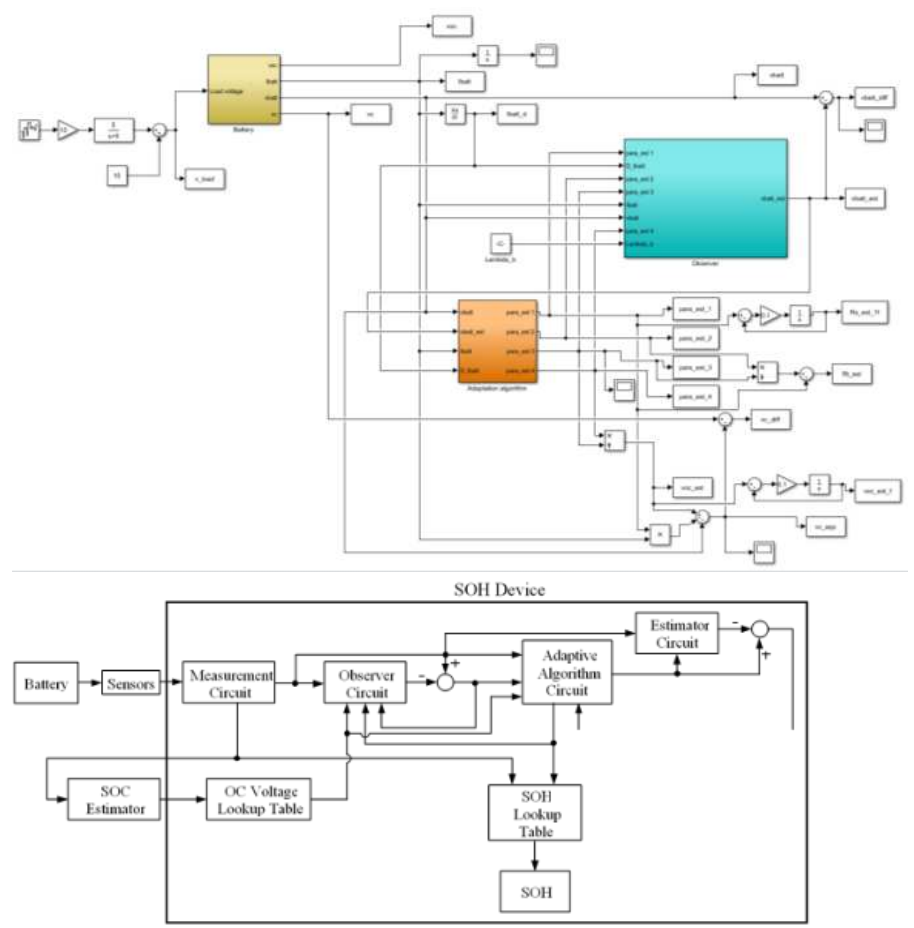

Figure 2. Adaptive control algorithm has been applied in estimating parameters of open-circuit voltage (OCV) and Internal resistance (IR) by using battery terminal voltage and discharge current as input data

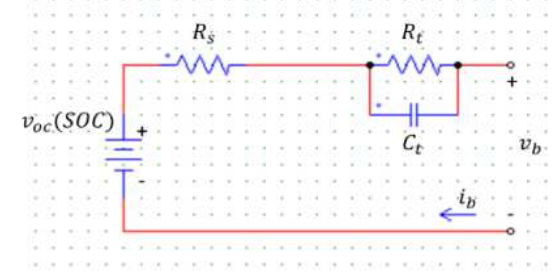

Figure 3. Electrical circuit modeling ( $v_{o c}$ : open-circuit voltage, $R_{s}$ :first-order resistance, $R_{t}$ :second-order resistance, and $C_{t}$ is capacitance of battery) 
Wu-Yang Sean and Ana Pacheco

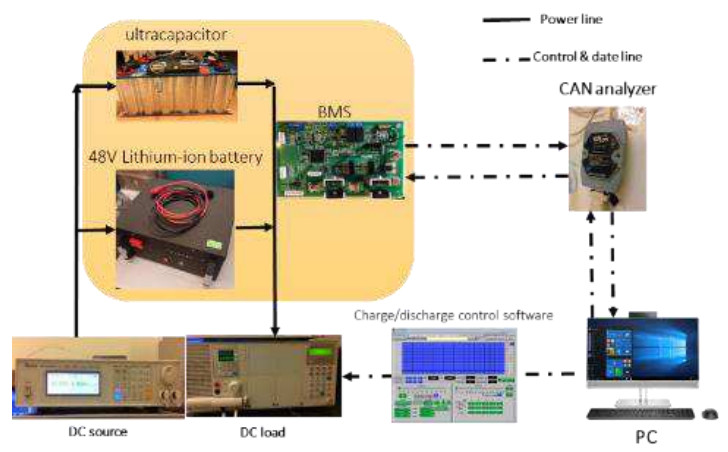

Figure 4. $52 \mathrm{~V} \mathrm{LiMnNiCoO}_{2}$ platform

Table 1. Specification of 52V LiMnNiCoO2 Pack

\begin{tabular}{|l|l|}
\hline \multicolumn{1}{|c|}{ Item } & \multicolumn{1}{c|}{ Specification } \\
\hline Construction & $13 \mathrm{~S} 6 \mathrm{P}$ \\
\hline Work Voltage & $39 \mathrm{~V}-52 \mathrm{~V}$ \\
\hline Normal Voltage (capacity) & $46.8 \mathrm{~V}$ \\
\hline Typical Capacity & $10 \mathrm{Ah}$ \\
\hline Cell type & $18650 \mathrm{AG}$ cell, capacity 2Ah \\
\hline EE function & OV/UV/OC/SC protection \\
\hline Communication function & CAN \\
\hline Discharge & Maximum 30A continuous \\
\hline Charge & Maximum 10A continuous \\
\hline Charger & Using existing charger \\
\hline
\end{tabular}
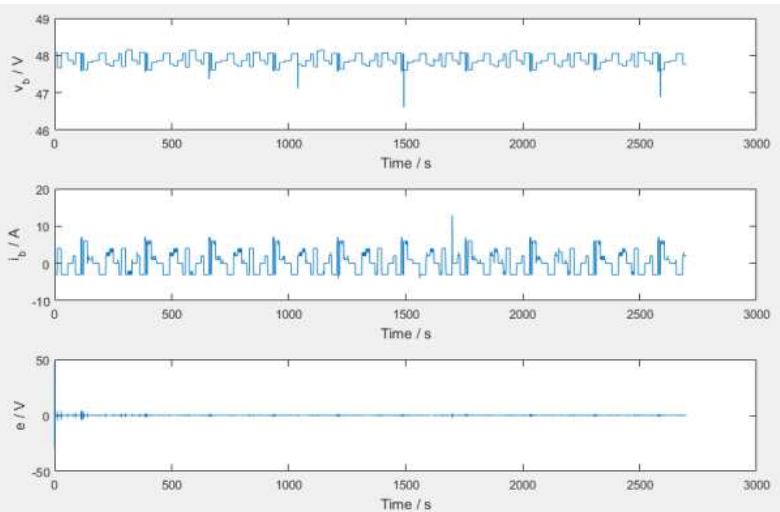

Figure 5. working voltage, working current, and convergent error of $10 \mathrm{Ah} / 52 \mathrm{~V}$ battery pack tested in the platform
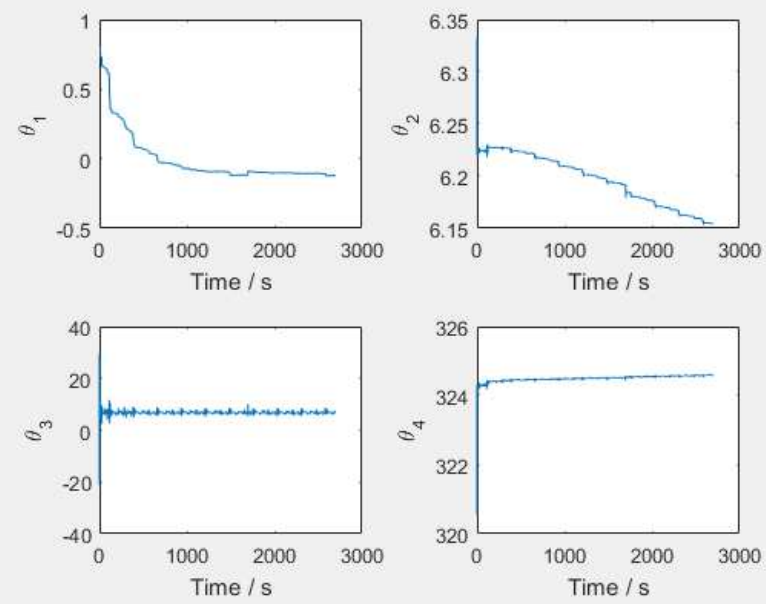

Figure 6. Estimated results of target parameters $\left(\theta^{T}=\right.$ $\left.\left[\begin{array}{llll}\theta_{1} & \theta_{2} & \theta_{3} & \theta_{4}\end{array}\right]^{T}\right)$

$\mathrm{R}_{\mathrm{s}} / \mathrm{Ohm}$ vs. Time/s



(a)

$\mathrm{R}_{\mathrm{t}} / \mathrm{Ohm}$ vs. Time/s

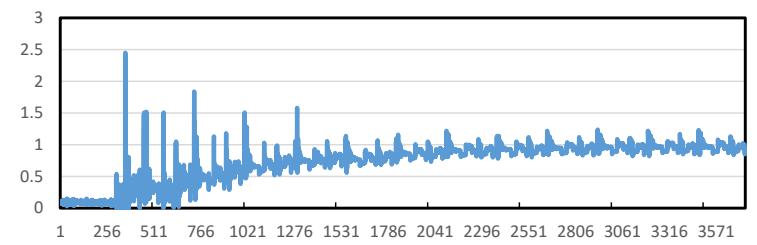

(b)

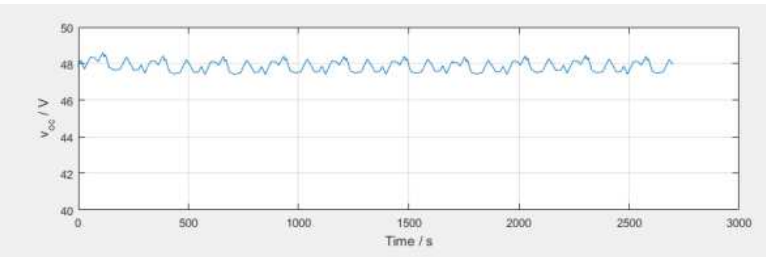

(c)

Figure 7. (a)(b)online estimated internal resistance and (c)open-circuit voltage 


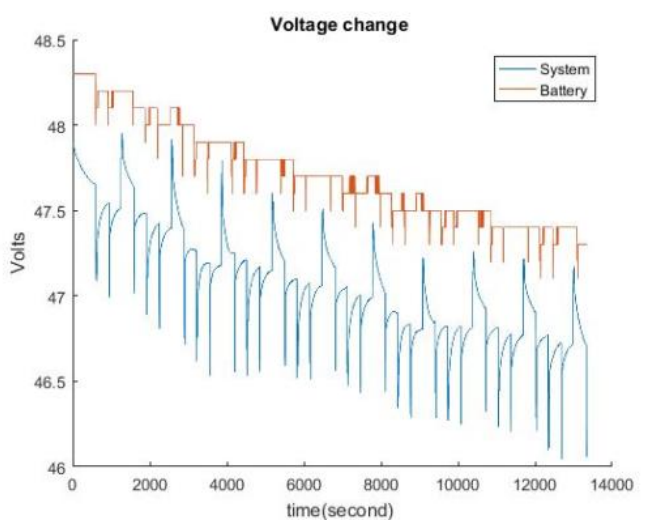

Figure 8 . Voltage drop of $25 \%$ battery $+75 \%$ UC (System: battery+UC, Battery: only battery)

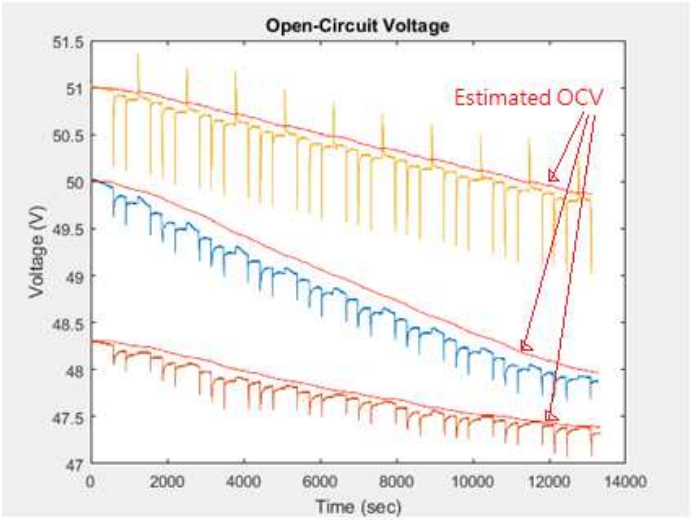

Figure 9. Comparison of measured voltage drop and estimated OCV of battery in cases of discharging ratio $0 \%, 25 \%$, and $75 \%$

\section{REFERENCES}

"Energy Conservation Measures for Wastewater Treatment." Water \& Wastewater Infrastructure (March 6, 2013): 269-314. doi:10.1201/b13968-23.

Sean W. Y., Chiang Y. H., Wu C. H., Liang Y. C., Ke J. C., and Lo S. M. 2010, "Feasibility of Hybrid Energy Storage System for Light Electric Vehicle", EVS-25, Shenzhen, China.

Wu, Chien-Hsun, Wu-Yang Sean, and Yi-Hsuan Hung. "Development of a Real-Time Simulator for Electric Vehicle with a Dual Energy Storage System." 2009 2nd International Conference on Power Electronics and Intelligent Transportation System (PEITS) (December 2009). doi:10.1109/peits.2009.5406798.

Chiang, Yi-Hsien, Wu-Yang Sean, Chien-Hsun Wu, and Chih-Yung Huang. "Development of a Converterless Energy Management System for Reusing Automotive Lithium-Ion Battery Applied in Smart-Grid Balancing." Journal of Cleaner Production 156 (July 2017): 750-756. doi:10.1016/j.jclepro.2017.04.028.
Chiang, Yi-Hsien, Wu-Yang Sean, and Se-Min Jeong. "Current Control of Energy Management System by Applying Ultracapacitor with Boost Converter Interface for Reused Lithium-Ion Battery." Journal of Cleaner Production 220 (May 2019): 945-952. doi:10.1016/j.jclepro.2019.02.107.

Chiang, Yi-Hsien, Wu-Yang Sean, and Jia-Cheng Ke. "Online Estimation of Internal Resistance and Open-Circuit Voltage of Lithium-Ion Batteries in Electric Vehicles." Journal of Power Sources 196, no. 8 (April 2011): 3921-3932. doi:10.1016/j.jpowsour.2011.01.005.

Pei, Lei, Chunbo Zhu, Tiansi Wang, Rengui Lu, and C.C. Chan. "Online Peak Power Prediction Based on a Parameter and State Estimator for Lithium-Ion Batteries in Electric Vehicles." Energy 66 (March 2014): 766-778. doi:10.1016/j.energy.2014.02.009.

Feng, Fei, Rengui Lu, and Chunbo Zhu. "A Combined State of Charge Estimation Method for Lithium-Ion Batteries Used in a Wide Ambient Temperature Range." Energies 7, no. 5 (May 2, 2014): 3004 3032. doi:10.3390/en7053004.

Plett, Gregory L. "Extended Kalman Filtering for Battery Management Systems of LiPB-Based HEV Battery Packs." Journal of Power Sources 134, no. 2 (August 2004): 277-292. doi:10.1016/j.jpowsour.2004.02.033.

Xiong, Rui, Hongwen He, Fengchun Sun, Xinlei Liu, and Zhentong Liu. "Model-Based State of Charge and Peak Power Capability Joint Estimation of LithiumIon Battery in Plug-in Hybrid Electric Vehicles." Journal of Power Sources 229 (May 2013): 159169. doi:10.1016/j.jpowsour.2012.12.003.

Li, Xiaoyu, Kai Song, Guo Wei, Rengui Lu, and Chunbo Zhu. "A Novel Grouping Method for Lithium Iron Phosphate Batteries Based on a Fractional Joint Kalman Filter and a New Modified K-Means Clustering Algorithm." Energies 8, no. 8 (July 28, 2015): 7703-7728. doi:10.3390/en8087703.

http://www.mpoweruk.com/performance.htm.

Feng, Fei, Rengui Lu, Guo Wei, and Chunbo Zhu. "Online Estimation of Model Parameters and State of Charge of LiFePO4 Batteries Using a Novel Open-Circuit Voltage at Various Ambient Temperatures." Energies 8, no. 4 (April 16, 2015): 2950-2976. doi:10.3390/en8042950.

Lu, J., 2013. "Development of fast one-dimensional model for prediction of coupled electrochemicalthermal behavior of Lithium-ion batteries" (Doctoral dissertation, The Ohio State University).

Argaw, N. "Renewable Energy in Water and Wastewater Treatment Applications; Period of Performance: April 1, 2001--September 1, 2001" (June 1, 2003). doi:10.2172/15004055. 
Olsson, Gustaf. "Water and Energy: Threats and Opportunities." Water Intelligence Online 11 (June 2012). doi:10.2166/9781780400693.

Mielke, E., Anadon, L. D., and Narayanamurti, V., 2010. "Water consumption of energy resource extraction, processing, and conversion." Belfer Center for Science and International Affairs.

Hardberger, Amy, Ashlynn S. Stillwell, Carey W. King, Michael Webber, and Ian J. Duncan. "Energy-Water Nexus in Texas." SSRN Electronic Journal (2009). doi:10.2139/ssrn.1873566.

Park L. and Croyle K., 2012. "California Water-Energy Nexus : Pathways to Implementation", GEI Consultants, Inc, Tech. Rep.
Kokabian, Bahareh, and Veera Gnaneswar Gude. "Photosynthetic Microbial Desalination Cells (PMDCs) for Clean Energy, Water and Biomass Production." Environmental Science: Processes \& Impacts 15, no. $12 \quad$ (2013): 2178. doi:10.1039/c3em00415e.

Sepehri, Arsalan, and Mohammad-Hossein Sarrafzadeh. "Effect of Nitrifiers Community on Fouling Mitigation and Nitrification Efficiency in a Membrane Bioreactor." Chemical Engineering and Processing - Process Intensification 128 (June 2018): 10-18. doi:10.1016/j.cep.2018.04.006. 
Declarations

1. Availability of data and materials Most the materials is published in the thesis listed below:

https://ethesis.lib.cycu.edu.tw/etdservice/view_metadata?etdun=U0017$1308201919200700 \& q u e r y \_f i e l d 1=\& \& q u e r y \_w o r d 1=\% \mathrm{E} 8 \% \mathrm{~A} 2 \% 81 \% \mathrm{E} 6 \% 96 \% 87 \% \mathrm{E} 7 \% 92 \% 9 \mathrm{E} \&$

2. Competing interests

Not applicable

3. Funding

Not applicable

4. Authors' contributions

Ana Pacheco integrated lithium-ion battery pack with in-house BMS and tested in the platform. WY Sean performed the life-cycle estimation based on adaptive control theory, and was a major contributor in writing the manuscript. All authors read and approved the final manuscript.

5. Acknowledgements

We appreciate for the suggestions from Dr. Yi-Hsien Chiang and his strong support in this project. 
Figures

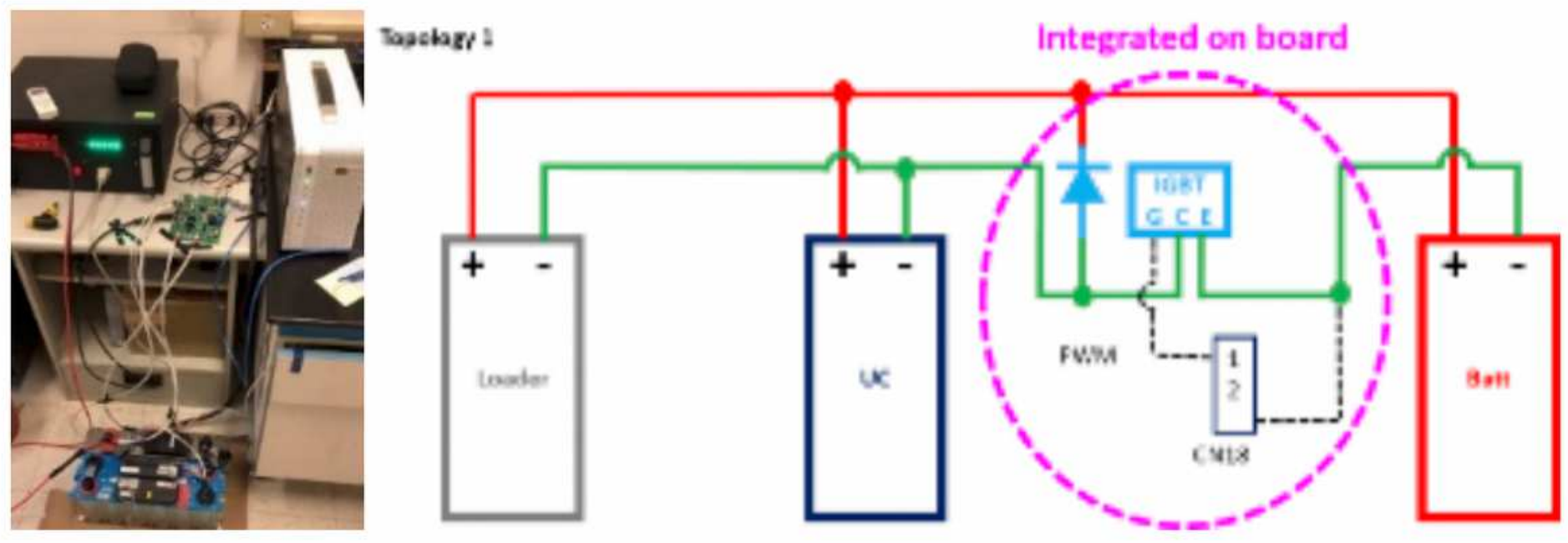

Figure 1

Battery(Batt in figure) in parallel connection with UC(ultracapacitor) controlled by PWM integrated in BMS 

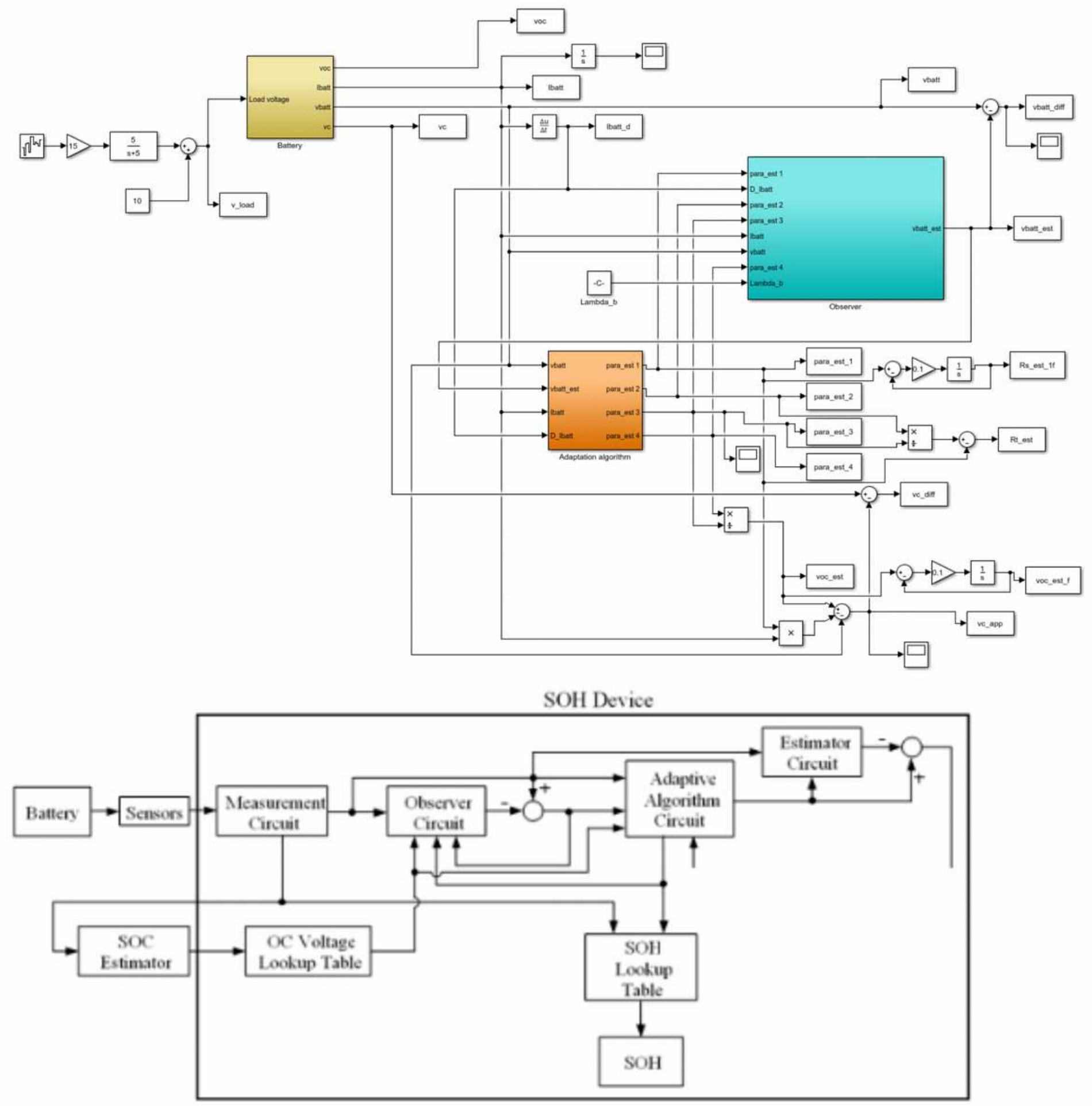

\section{Figure 2}

Adaptive control algorithm has been applied in estimating parameters of open-circuit voltage (OCV) and Internal resistance (IR) by using battery terminal voltage and discharge current as input data 


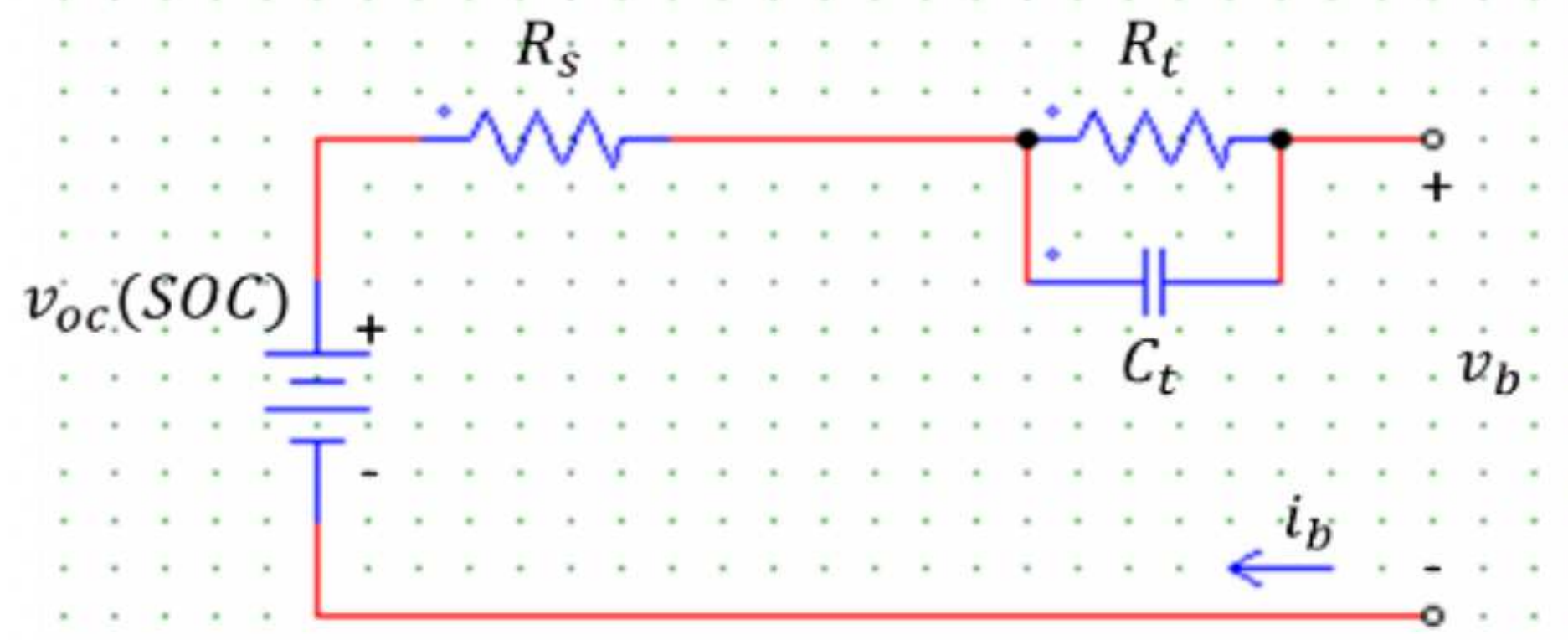

Figure 3

Electrical circuit modeling (\_oc: open-circuit voltage, R_s:first-order resistance, R_t:second-order resistance, and C_t is capacitance of battery) 


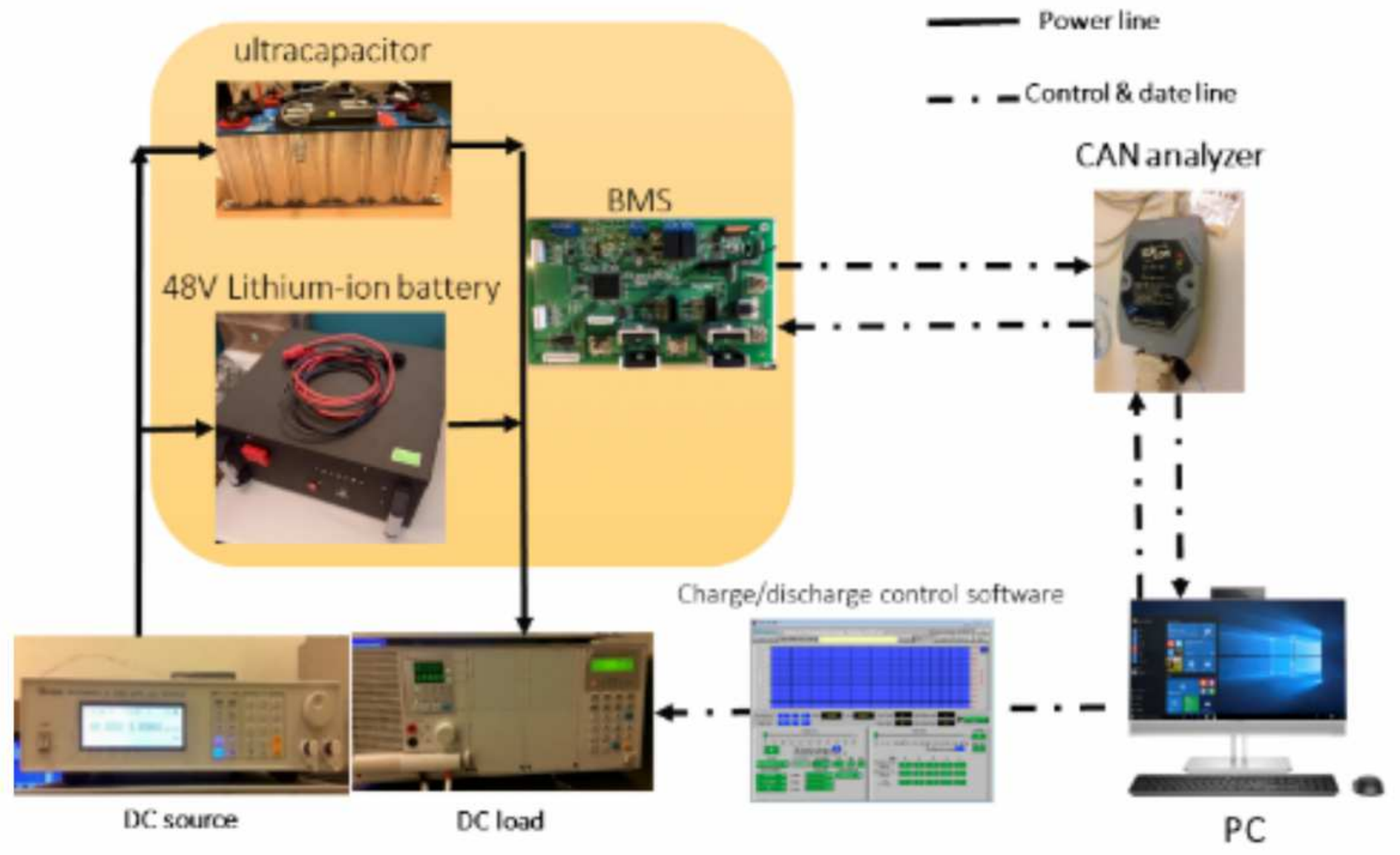

Figure 4

52V LiMnNiCoO2 platform 



Figure 5

working voltage, working current, and convergent error of $10 \mathrm{Ah} / 52 \mathrm{~V}$ battery pack tested in the platform 

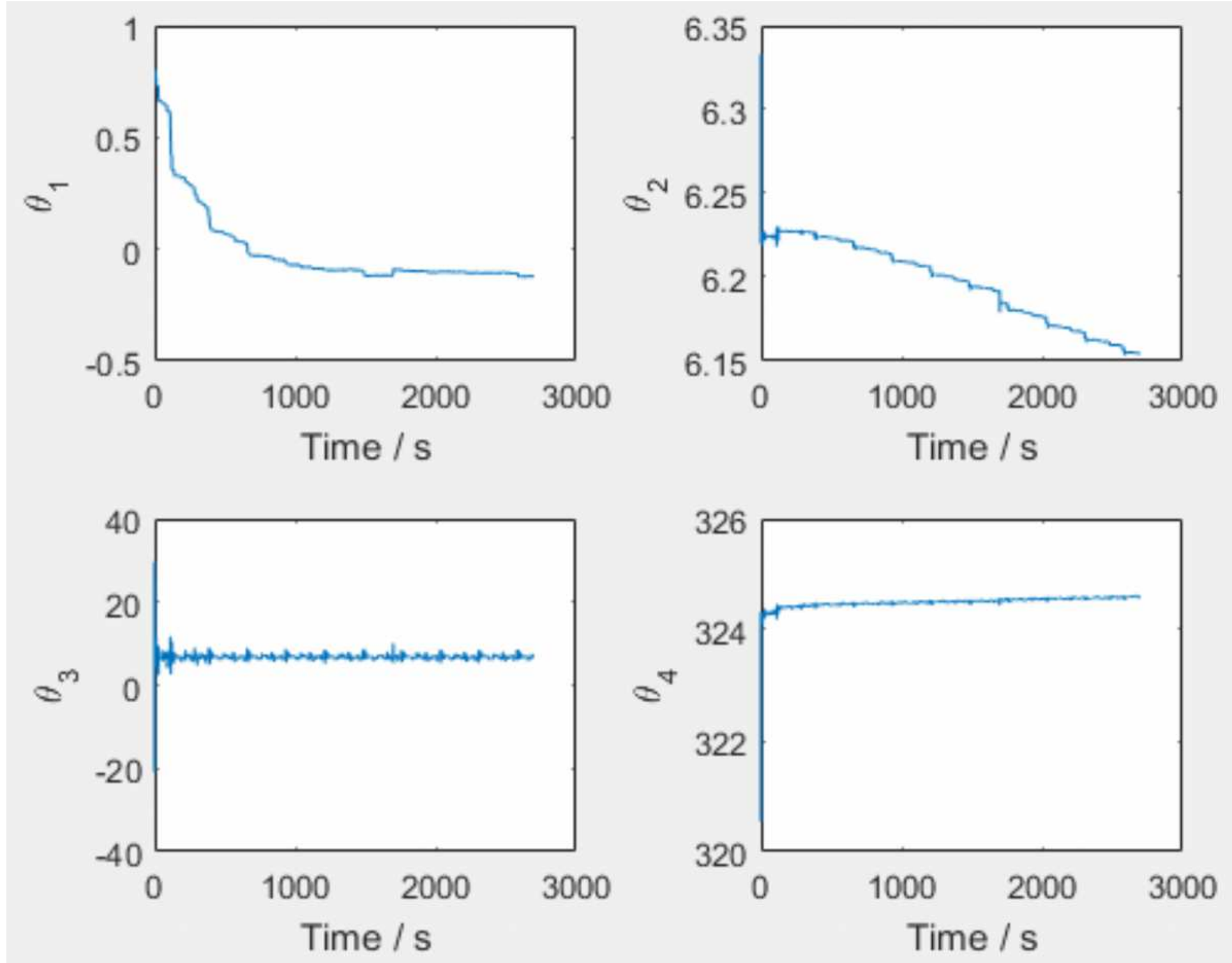

Figure 6

Estimated results of target parameters $\left(\theta^{\wedge} T=\mathbb{Q}\left[\theta_{-} 1 \theta_{-} 2 \theta_{-} 3 \theta_{-} 4\right] \mathbb{\bigotimes}^{\wedge} T\right)$ 
$\mathrm{R}_{\mathrm{s}} / \mathrm{Ohm}$ vs. Time/s



(a)

$\mathrm{R}_{\mathrm{t}} / \mathrm{Ohm}$ vs. Time/s



(b)

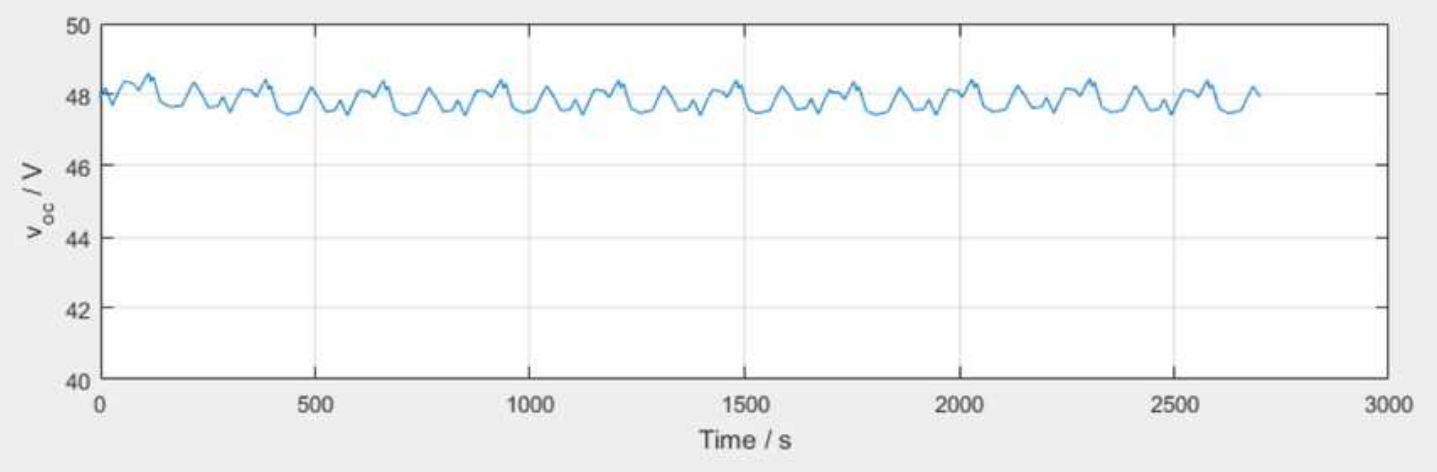

(c)

Figure 7

(a)(b)online estimated internal resistance and (c)open-circuit voltage 


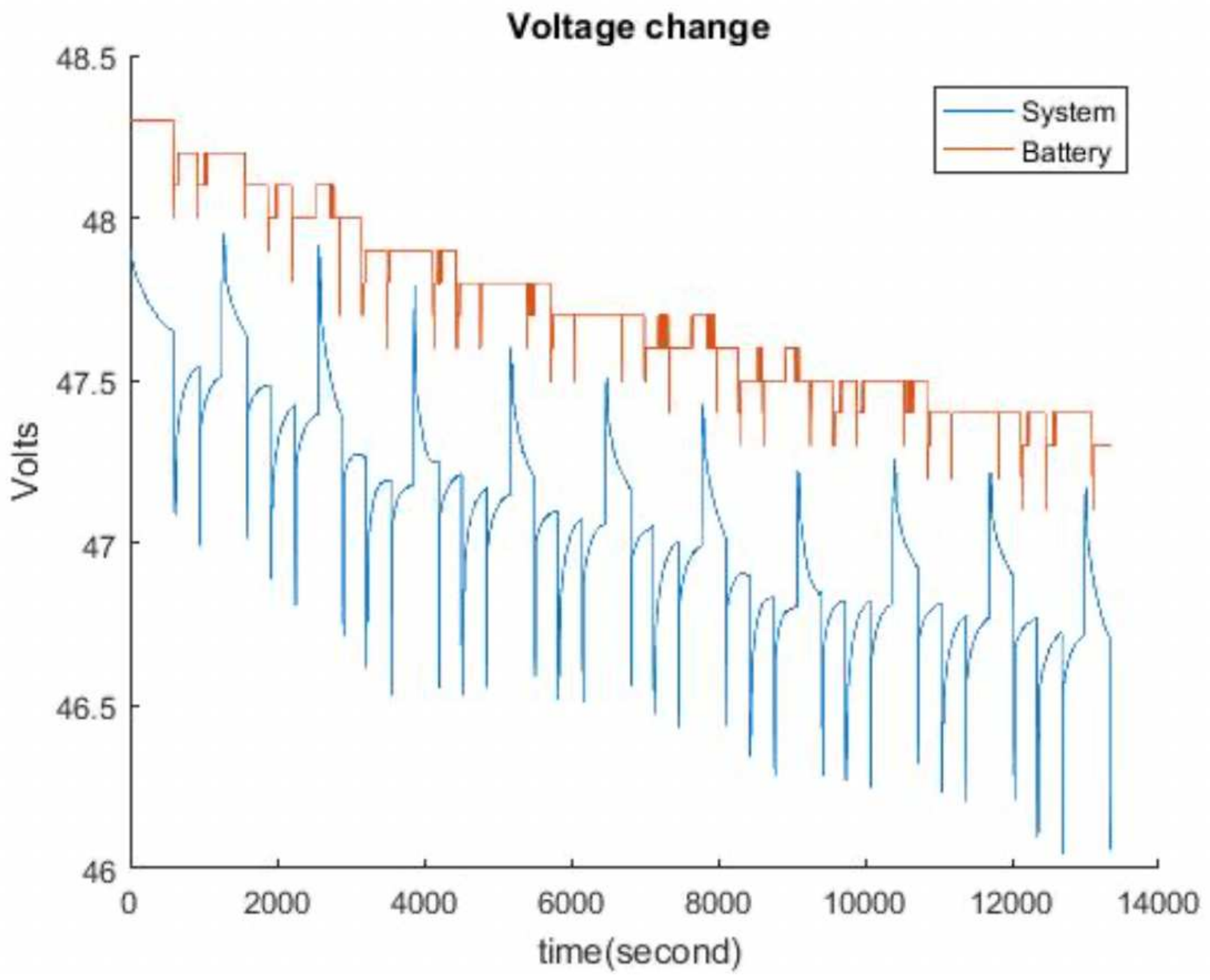

Figure 8

Voltage drop of $25 \%$ battery $+75 \%$ UC (System: battery+UC, Battery: only battery) 


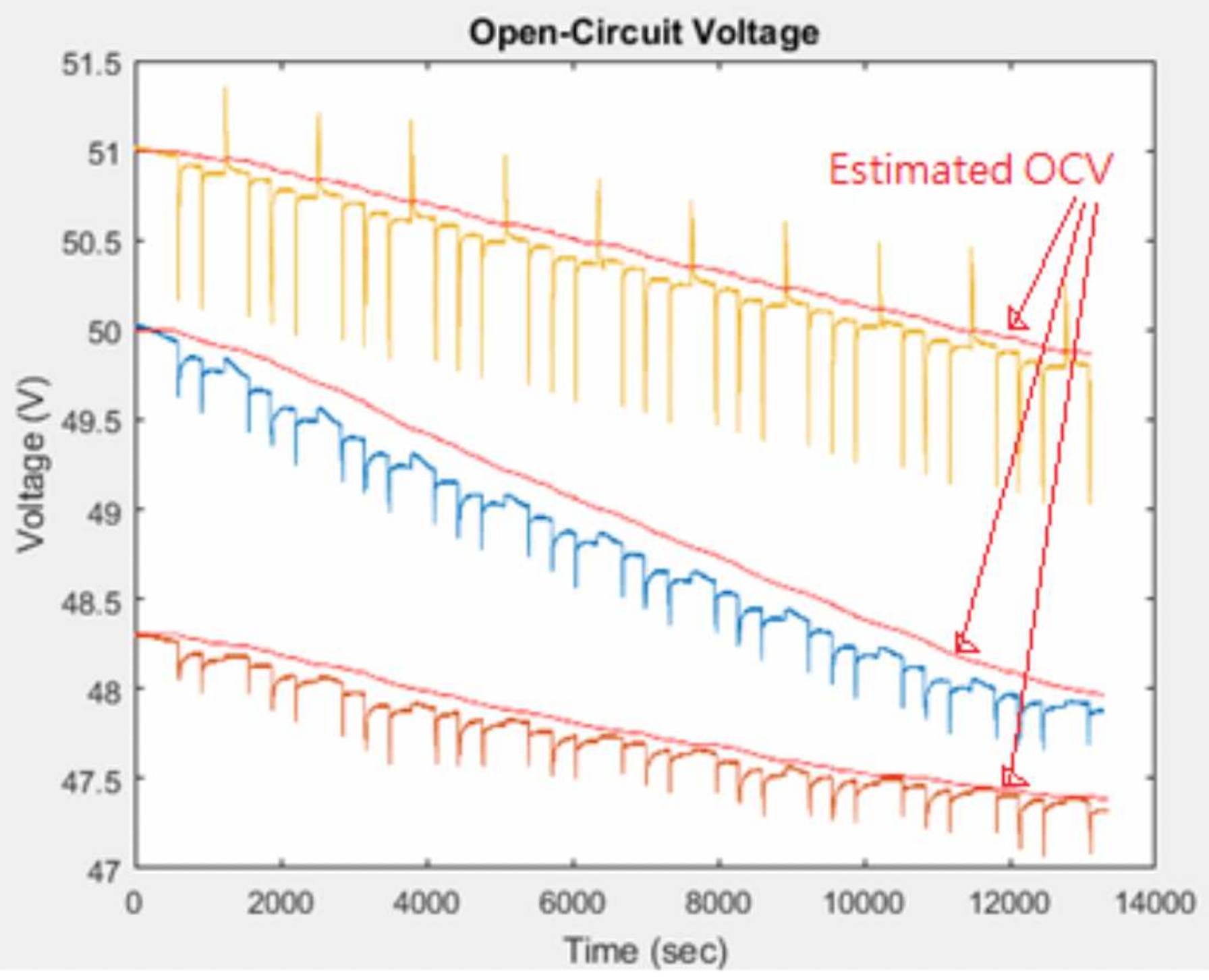

Figure 9

Comparison of measured voltage drop and estimated OCV of battery in cases of discharging ratio $0 \%$, $25 \%$, and $75 \%$ 